In the programme of research which has been under consideration by the Heating and Ventilation Committee of the Department, on which are members of the Institution of Heating and Ventilating

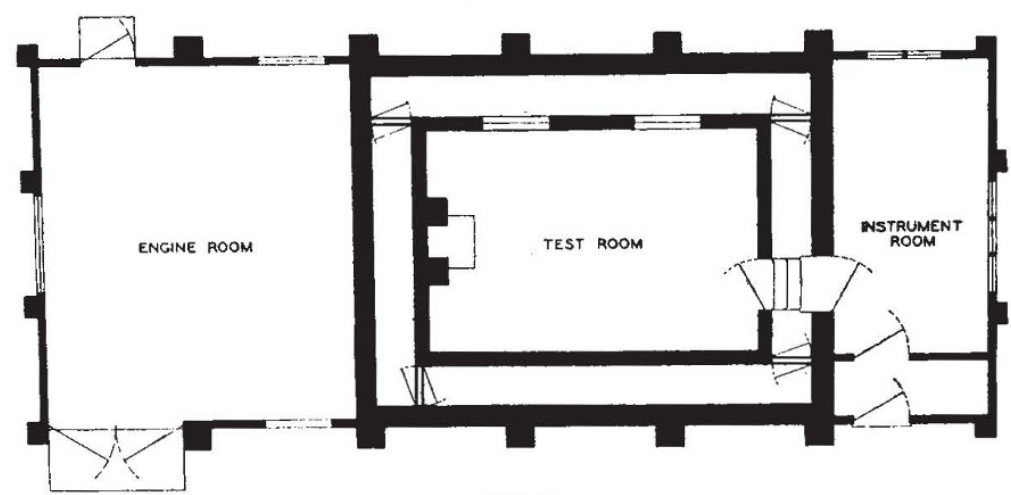

FIG. 2.

Engineers, emphasis has been placed upon the study of the conditions obtaining in a room warmed by extended surface heating and upon the investigation of floor and ceiling heating. It should perhaps be made clear that the new laboratory is specially designed for comparative work, and in the examination of floor heating, for example, it is clearly important to obtain an adequate comparison with other forms of heating. The most common form of central heating in use at the present time is by cast-iron radiators, and it is proposed, therefore, to adopt this as a standard of reference. This will not only provide a very convenient 'yardstick' but will also ensure that a substantial body of data will be obtained relative to this important type of heating.

The new laboratory was open for inspection on the occasion of the annual visit of the Institution of Heating and Ventilating Engineers on July 22, when the members were received by Sir Raymond Unwin, the chairman of the Building Research Board, and the laboratory was formally opened by Sir Frank Smith, secretary of the Department of Scientific and Industrial Research.

\title{
Petroleum Fuels in Canada
}

$\mathrm{D}^{\mathrm{u}}$ URING recent years, importers and consumers of petroleum fuels in Canada have furnished statistics of deliveries and uses of these products to the Department of Mines. Resulting from correlation of data supplied, a report has been prepared entitled "Petroleum Fuels in Canada" (Department of Mines, Bulletin 772; 1936) from which many interesting facts emerge.

Fuels are divided into four classes: fuel oil, kerosene, gasoline and petroleum coke; after summary tables showing quantities of each marketed in Canada during 1933 and 1934, and amounts distributed in each of the Provinces, the classes are studied separately. In 1934 more than 86 per cent of the total fuel oil was processed in Canadian refineries, the rest being imported; of this, 26 per cent was used for domestic heating, 23 per cent for industrial heating and power, more than 5 per cent for tractor fuel and more than 46 per cent for rail and water transportations. In the same year deliveries of kerosene were less than one eleventh of the volume of fuel oil and represented only one twenty-fifth of the total of petroleum fuels; actually only $36 \cdot 2$ million gallons were delivered in Canada, which is substantially less than was delivered in 1933; approximately 66 per cent of this was used for domestic heating, cooking and lighting, 24.5 per cent for tractor fuel and the remainder for other general uses.

Gasoline statistics included in the report are not strictly comparable with those of fuel oil and kerosene as they represent totals recorded by provincial tax departments of the Bureau and are interpreted subject to provisos as to amounts sold, etc., effective each year in each province. The gallonages supplied under each purpose use are therefore treated as estimates; nevertheless tables showing gasoline sales by provinces and quantities sold for motoring and other purposes are of interest as indication of destination of gasoline marketed in Canada.

Petroleum coke is used primarily as a fuel for domestic and industrial heating but is also a useful component of electric batteries, carbon lamps, crucibles and other manufactured articles ; in 1934 approximately 57,000 short tons were sold for fuel, of which about 39,000 tons were destined for domestic heating and 18,000 for industrial heating.

\section{Problems of Translocation in the Plant}

$\mathrm{M}^{\mathrm{s}}$ ESSRS. Mason, Maskell and Phillis continue their analysis of the movement of substances in the cotton plant in two papers published in the Annals of Botany (50, January 1936).

They first give their reasons for rejecting, on present evidence, either the Münch theory of mass flow in the phloem, or the theory of protoplasmic streaming, as providing a satisfactory mechanism for the movements that take place. Any view of mechanism must be influenced by definite information as to whether the phloem can function at the same time to deliver different materials in opposite directions, and these two papers describe the results of experiments designed to elucidate this point. The first paper (by Mason, Maskell and Phillis) shows that whilst very slow import of sugar into darkened 
leaves is suggested by a formation of starch around the veins of such leaves when they remain in com. munication with illuminated foliage, yet the behaviour of such darkened leaves isolated by rings as compared with non-isolated leaves does not permit a safe conclusion that sugar may still move in whilst nitrogen moves out. Experiments with defoliated plants with tops in a humid atmosphere suggest that even when transpiration is so reduced, the nitrogen supply of the tops can still be adequately furnished by the xylem. An attempt by suitable ringing technique to demonstrate the movement of stored nitrogen from a basal adult region of the shoot upward into the growing tops when sugars were moving downwards was more promising, but the authors recognize that this stored nitrogen may still have moved down to the roots via the phloem and then upwards via the xylem if the nitrogen is released into the tracheæ in the root.

The later experiment, by Phillis and Mason, is regarded by its authors as giving a more definite answer on the point at issue. The cotton plants in this experiment were all ringed at the base, the basal leaves darkened and one series ringed between the basal region and the apical region. In this case when the plants were starved of all phloem mobile elements, the nitrogen travelled upwards in considerable amount from the basal to the apical region when these were not separated by a ring, whilst little or none entered the apical region when separated by a ring from the basal region.

As carbohydrate was still passing downwards from apical to basal regions in the same plant, these experiments are regarded as supplying good evidence that sugar and nitrogen may travel simultaneously in opposite directions through the phloem.

\section{Science News a Century Ago}

\section{The British Association at Bristol}

THE work of the British Association at its first Bristol meeting began on Monday, August 22, 1836, there being seven sections, namely, Mathematical and Physical Science, Chemistry and Mineralogy, Geology and Geography, Zoology and Botany, Medicine, Statistics and Mechanical Science. Among the cuntributors of papers were Brewster, Baily, Lubbock, Whewell, Hamilton, Babbage, Sedgwick, Buckland, Conybeare, Daubeny, Murchison, Dr. Hare of Philadelphia, Lardner, Snow Harris and Scott Russell.

The general meeting of the Association was held on the evening of August 22 in the Theatre, when some 2,000 persons were present. The Rev. Dr. Lloyd, Provost of 'Trinity College, Dublin, the retiring president, was in the chair, and in the course of his address said that among the purposes of the Associa. tion was that "by a more rapid and extensive com. munication of the lights of science as they are struck out, and by carrying these things home to the doors of all, to awaken to exertion those gigantic powers of mind, which are not confined to a few favoured spots; but which are everywhere to be found; and by establishing a more immediate and intimate communication among those engaged in kindred pursuits, to unite their exertions, as it were, into one simultaneous effort, and thereby to accelerate the progress of discovery in every line in which the mysteries of nature may be penetrated by the ingenuity and perseverance of man".

At the conclusion of his address, Dr. Lloyd resigned the chair to the Marquis of Northampton, whose first action was to invite some of the ladies present who were without seats to occupy places on the stage, although they were "by law excluded from the plat. form reserved for the General Committee". His Lordship congratulated the meeting on the great accession of members the Association had received at Bristol. "Here," he said, "were men of every shade of denomination and opinion engaged in one united effort in the cause of science and trutheminent men from foreign lands, united by the glorious brotherhood of mind, were here assembled to cement the intellectual union of nations. This he regarded as a political result of the highest and most gratifying order. The moral effect of the Association arose from truth being the great object of all its labours."

\section{Death of Louis-Marie-Henri Navier}

ON August 23, 1836, the eminent French engineer Louis-Marie-Henri Navier died in Paris at the age of fifty-one years. He was the son of a well-known lawyer of Dijon, where he was born on February 15, 1785. As a boy, owing to the death of his father, Navier came under the influence of his uncle EmilianMarie Gauthey (1732-1806), an inspector-general of the Corps des Ponts et Chaussées. At the age of seventeen years, he entered the Ecole Polytechnique and two years later the Ecole des Ponts et Chaussées, the Government school for civil engineers founded in 1747 under the directorship of Perronet, and in 1804 directed by Prony. The mathematical training Navier received in these famous schools was reflected in all his later work. His first literary work was the publication of his uncle's "Traité de la Construction des Ponts", 1813. In 1819 he was made a professor of mechanics in the Ecole des Ponts et Chaussées, and in the same year contributed to the Paris Academy of Sciences his "Mémoire sur la flexion des verges élastiques courbes", which was followed by his "Mémoire sur les lois de l'équilibre et du mouve. ment des corps solides élastiques", 1821, and his "Rapport et mémoire sur les ponts suspendus", 1824. In 1827 he investigated the general equations of equilibrium of an elastic solid, starting from an assumption as to the molecular constitution of matter.

While engaged in teaching and writing, Navier was responsible at the same time for the design of bridges, among which was a chain suspension bridge over the Seine at the Invalides in Paris, the bars for which he required to be tested to 11 tons per sq. in. Constructed in 1826, unfortunately one of the pylons failed, and the bridge had to be taken down. It was afterwards shown by Prony that the mishap was due to circumstances the designer could not have foreseen. The incident for a time had an unfavourable effect on Navier's reputation; but the esteem in which he was held was shown by his appointment in 1830 to the chair of analysis and mechanics at the École Polytechnique. Two years before his death he was given the rank of divisional inspector in the Corps des Ponts et Chaussées. His collected works were published after his death, and to the third edition of them Saint Venant added many valuable notes and corrections. 